\title{
Enhancing anaerobic digestion performance of crude lipid in food waste by enzymatic pretreatment
}

\author{
Ying Meng ${ }^{\mathrm{a}, \mathrm{b}}$, Fubo Luan ${ }^{\mathrm{b}}$, Hairong Yuan ${ }^{\mathrm{a}}$, Xue Chen ${ }^{\mathrm{c}}$, Xiujin Li ${ }^{\mathrm{a}, *}$ \\ ${ }^{a}$ Department of Environmental Science and Engineering, Beijing University of Chemical Technology, 15 Beisanhuan East Road, Chaoyang District, Beijing 100029, China \\ ${ }^{\mathrm{b}}$ State Key Laboratory of Environmental Aquatic Chemistry, Research Center for Eco-Environmental Sciences, Chinese Academy of Sciences, Beijing 100085, China \\ ${ }^{\mathrm{c}}$ China Power Conservation E Environment Protection CO., LTD, Beijing 100020, China
}

\section{H I G H L I G H T S}

- Three lipases were applied to hydrolyze the floatable grease in the food waste.

- Animal fat and vegetable oil are applied as substrates for anaerobic digestion.

- Three lipids are hydrolyzed in the conditions of $24 \mathrm{~h}, 1000-1500 \mu \mathrm{L}$ and $40-50{ }^{\circ} \mathrm{C}$.

- The digestion time was shortened by $10-40 \mathrm{~d}$ for three lipids treated by lipases.

- The biomethane production rate of the hydrolysis products was enhanced 26.9-157.7\%.

\section{A R T I C L E I N F O}

\section{Article history:}

Received 27 July 2016

Received in revised form 9 October 2016

Accepted 19 October 2016

Available online 21 October 2016

\section{Keywords:}

Lipase

Hydrolysis

Crude lipid

Anaerobic digestion

\begin{abstract}
A B S T R A C T
Three lipases were applied to hydrolyze the floatable grease (FG) in the food waste for eliminating FG inhibition and enhancing digestion performance in anaerobic process. Lipase-I, Lipase-II, and Lipase-III obtained from different sources were used. Animal fat (AF) and vegetable oil (VO) are major crude lipids in Chinese food waste, therefore, applied as substrates for anaerobic digestion tests. The results showed that Lipase-I and Lipase-II were capable of obviously releasing long chain fatty acid in AF, VO, and FG when hydrolyzed in the conditions of $24 \mathrm{~h}, 1000-1500 \mu \mathrm{L}$ and $40-50{ }^{\circ} \mathrm{C}$. Compared to the untreated controls, the biomethane production rate were increased by $80.8-157.7 \%, 26.9-53.8 \%$, and $37.0-40.7 \%$ for AF, VO, and FG, respectively, and the digestion time was shortened by $10-40 \mathrm{~d}$. The finding suggests that pretreating lipids with appropriate lipase could be one of effective methods for enhancing anaerobic digestion of food waste rich in crude lipid.
\end{abstract}

(c) 2016 Published by Elsevier Ltd.

\section{Introduction}

Chinese food waste is characterized by high amount of organic matters, including crude lipid (22.8-31.45\%), crude protein (14.7128.64\%), and carbohydrates on dry matter bases (Meng et al., 2015a). Food waste is therefore suitable to be used to produce biogas through anaerobic digestion. Anaerobic digestion has received increasing attentions in recent years for its advantages of reducing waste pollution and produce clean energy as well (Cho et al., 2016; Dhamodharan et al., 2015; Naroznova et al., 2015).

The lipid is one of major contents in food waste. It is a mixture of vegetable oils and animal fats (Meng et al., 2015a). The production of vegetable oils and animal fats were about 160 million tons

\footnotetext{
* Corresponding author at: 15 Beisanhuan East Road, Chaoyang District, Beijing 100029, China.

E-mail addresses: xjlibuct@gmail.com, xjli@mail.buct.edu.cn (X. Li).
}

per year in global level (Lin et al., 2013). Approximately $80 \%$ of total oils and fats were used for human food consumption (Rosillo-Calle et al., 2009). Compared to the food waste in other countries, Chinese food waste contains higher crude lipids due to specific dietary habits in China. The crude lipids in Chinese food waste were found to be mainly comprised of animal fat and vegetable oil. Although food waste contains high contents of readily biodegradable compositions such as protein, carbonhydrates, the direct digestion without any pretreatment of crude lipids could lead to low digestion efficiency and severe inhibition to anaerobic process due to the slow degradation rate and the accumulation of crude lipid in digester (Chen et al., 2008; Meng et al., 2015b). It was found that the digestion of lipid is the rate-limiting step in the digestion process of food waste (Sun et al., 2014). Therefore, it would be critical to find effective methods to eliminate the limitation for achieving high performance of food waste anaerobic 
digestion. The lipase pre-hydrolysis of crude lipids could be one of options.

Lipase has been applied in the treatment of lipid-rich wastewater by anaerobic process. The pre-hydrolysis stage could enhance the anaerobic digestion efficiency of wastewater from meatprocessing plant (Cavaleiro et al., 2013; Luste et al., 2009; Masse et al., 2003) and babassu oil processing industry (Valladão et al., 2007). High chemical oxygen demand removal efficiency was obtained in the lipase-treated dairy wastewater (Mendes et al., 2006; Rosa et al., 2009) and fish-processing plant wastewater (Alexandre et al., 2011). Additionally, lipase pretreatment could increase the organic load of lipid-rich waste water in a hybrid UASB reactor (Gomes et al., 2011).

It was also found that treatment with pancreatic lipase significantly reduced the size of pork fat particles, enhanced the concentration of long chain fatty acid (LCFA) and decreased the digestion time in slaughterhouse wastewater (Masse et al., 2003; Mendes et al., 2006). In a recent study, we found that lipase addition could enhance the biomethane production of food waste (Meng et al., 2015a). These studies have provided important insight that lipase pretreatment is a possible strategy to minimize the inhibition of lipid accumulation in food waste digester. What remained unclear is if and how the lipases from different sources influence the digestion performance of crude lipid in Chinese food waste.

In this study, three lipases were applied to hydrolyze the floatable grease (FG) in Chinese food waste for eliminating FG inhibition and enhancing digestion performance in anaerobic process. The purpose of the study is to investigate the feasibility of lipase pretreatment and also determine lipase pretreatment parameters.

\section{Materials and methods}

\subsection{Substrate and inoculum}

Animal fat (AF), vegetable oil (VO), and floatable grease (FG) skimmed from food waste are collectively called FOG in this study. FOG was employed to investigate the effect of lipase pretreatment on biomethane production in anaerobic digestion process. AF was lard that rendered down dryly by hands. VO was arachis oil purchased from the supermarket. FG was skimmed from food waste after centrifuging (Meng et al., 2015b). The food waste was collected from cafeteria at Beijing University of Chemical Technology (BUCT). The saponification values of $\mathrm{AF}, \mathrm{VO}$ and $\mathrm{FG}$ were $184.9 \pm 0.3 \mathrm{mg} \mathrm{KOH} / \mathrm{g}, \quad 185.3 \pm 0.5 \mathrm{mg} \mathrm{KOH} / \mathrm{g} \quad$ and $188.6 \pm 0.2 \mathrm{mg} \mathrm{KOH} / \mathrm{g}$, respectively. The $\mathrm{AF}$, VO and FG were sealed up and stored at $4{ }^{\circ} \mathrm{C}$ to prevent biological decomposition. The inoculum was obtained from the effluent of an anaerobic digester treating pig manure (Nanwu biogas plant at Shunyi District, Beijing, China). The contents of total solid (TS) and volatile solid (VS) were $3.53 \pm 0.06 \%$ and $1.95 \pm 0.03 \%$, respectively.

The properties of lipases used are presented in Table 1. Lipase-I, Lipase-II and Lipase-III are purchased from different companies listed in Table 1. The sources of three lipases are Aspergillus, Candida and Porcine pancreatic, respectively. Both Lipase-I and Lipase-II are produced by submerged fermentation. But the carbon sources of Lipase-II during the fermentation are refined vegetable oil and vegetable protein. The enzyme activity values of Lipase-I and Lipase-II are same $(100 \mu / \mathrm{mg})$ which could be applied in wide range of $\mathrm{pH}$ and temperature. Lipase-III is natural lipase that extracted from porcine pancreatic, which is purchased from Sigma-Aldrich are effective at $\mathrm{pH} 7.4-7.7$ at $37^{\circ} \mathrm{C}$.

\subsection{Anaerobic digestion tests of hydrolyzed FOG}

\subsubsection{Enzymatic hydrolysis of the FOG}

To obtain appropriate application conditions for Lipase I-III, the hydrolysis time, volume used and temperature are investigated when FOG are hydrolyzed. In consideration of subsequent work about anaerobic digestion of FOG, $\mathrm{pH}$ was not adjusted during the hydrolysis process. Because initial $\mathrm{pH}$ of the mixture of FOG and lipase was nearly 7.0 which is in the suitable range (Table 1). Lipase-I, Lipase-II and Lipase-III are dissolved in deionized water (5.0 g lipase powder in $100 \mathrm{~mL}$ deionized water). Firstly, the hydrolysis time ( $0 \mathrm{~h}, 1 \mathrm{~h}, 2 \mathrm{~h}, 4 \mathrm{~h}, 8 \mathrm{~h}, 12 \mathrm{~h}, 24 \mathrm{~h}$ and $36 \mathrm{~h}$ ) was analyzed by adding $0.5 \mathrm{~g}$ FOG and $500 \mu \mathrm{L}$ enzymatic solution in incubator shaker $\left(40{ }^{\circ} \mathrm{C}, 200 \mathrm{rpm}\right)$. Then the volume of enzymatic solution $(50 \mu \mathrm{L}, 100 \mu \mathrm{L}, 200 \mu \mathrm{L}, 500 \mu \mathrm{L}, 1000 \mu \mathrm{L}, 1500 \mu \mathrm{L}$ and $2000 \mu \mathrm{L}$ ) was investigated at $40^{\circ} \mathrm{C}$. Lastly, hydrolysis reactions were taken place at four temperatures $\left(30^{\circ} \mathrm{C}, 40^{\circ} \mathrm{C}, 50^{\circ} \mathrm{C}\right.$ and $60{ }^{\circ} \mathrm{C}$ ) to obtain the maximum hydrolysis rate. The FOG would be hydrolyzed by the lipases at appropriate conditions (hydrolysis time, volume of addition and temperature). The hydrolysis products were analyzed by GC. All experiments were conducted in triplicate.

\subsubsection{Anaerobic biodegradability tests}

The anaerobic digestion of lipase treated FOG was conducted. When the FOG was hydrolyzed by lipase, the hydrolysis products were anaerobically digested in scrum bottles. The organic loads of $10 \mathrm{gVS} / \mathrm{L}$ and food-to-microorganism ratio (VS/VS) of 1.0 were employed for all digesters. After loading the required amounts of hydrolytic FOG and seeding sludge, each digester was filled up to $150 \mathrm{~mL}$ with tap water. Then the bottles were incubated in a shaker with temperature of $35 \pm 1{ }^{\circ} \mathrm{C}(5 \mathrm{~min} / \mathrm{h})$.

In order to evaluate the effects of the lipase addition on the hydrolysis of FOG, same amount of control FOG was digested in the same conditions without adding lipase. The daily biogas production and biomethane content were measured during entire digestion time. All experiments were conducted in triplicate.

\subsection{Analytical method}

TS and VS were determined according to Standard Methods for the Examination of Water and Wastewater (Wef, 1998). The saponification and acid value of FOG were determined according to Chinese National Standards (Ma et al., 2015).

The hydrolysis yields with LCFA were obtained after transesterification and extraction using n-Hexane. The amount of extracts were measured by a gas chromatography (SHIMADZU, GC2014) equipped with a DB-WAX column and a FID detector.

Table 1

The sources of three lipases purchased from different companies and their properties.

\begin{tabular}{|c|c|c|c|c|}
\hline Lipase & Sources & Companies & Application conditions & Enzyme activity \\
\hline Lipase I & Aspergillus & $\begin{array}{l}\text { JieNuo Enzyme Co., Ltd (Shandong province, } \\
\text { China) }\end{array}$ & $\begin{array}{l}\text { pH: } 6.0-13.0 \text { Temperature: } 20- \\
45^{\circ} \mathrm{C}\end{array}$ & $100 \mu / \mathrm{mg}\left(50^{\circ} \mathrm{C}, \mathrm{pH} 6.0\right)$ \\
\hline $\begin{array}{l}\text { Lipase } \\
\text { II }\end{array}$ & Candida & $\begin{array}{l}\text { Beijing CAT New Century Biotechnology Co., Ltd } \\
\text { (China) }\end{array}$ & $\begin{array}{l}\text { pH: 6.5-9.5 Temperature: } 25- \\
55^{\circ} \mathrm{C}\end{array}$ & $100 \mu / \mathrm{mg}$ \\
\hline $\begin{array}{l}\text { Lipase } \\
\text { III }\end{array}$ & $\begin{array}{l}\text { Porcine } \\
\text { pancreatic }\end{array}$ & SIGMA-ALDRICH (China) & pH: 7.4-7.7 Temperature: $37^{\circ} \mathrm{C}$ & $\begin{array}{l}100-400 \mu / \mathrm{mg} \text { protein (using olive oil ( } 30 \mathrm{~min} \\
\text { incubation)) }\end{array}$ \\
\hline
\end{tabular}


The carrier gas was $\mathrm{N}_{2}$ at $1.0 \mathrm{~mL} / \mathrm{min}$. The injection port and detector temperature were $250^{\circ} \mathrm{C}$ and $300{ }^{\circ} \mathrm{C}$, respectively. Initial oven temperature was $120^{\circ} \mathrm{C}$ for $3 \mathrm{~min}$, with a $20^{\circ} \mathrm{C} / \mathrm{min}$ ramp to $220^{\circ} \mathrm{C}$, and a finally isothermal for $12 \mathrm{~min}$.

The $\mathrm{H}_{2}, \mathrm{~N}_{2}, \mathrm{CH}_{4}$ and $\mathrm{CO}_{2}$ content in the biogas were analyzed by a gas chromatograph (SP2100A, Beifen-Ruili) equipped with a thermal conductivity detector (TCD) and a stainless steel column $(2 \mathrm{~m} \times 3 \mathrm{~mm})$. The final results from gas chromatography were the average of three different reads.

\subsection{Calculating methods}

\subsubsection{Hydrolysis rate}

The hydrolysis rate is defined as following (Wanasundara and Shahidi, 1998):

\section{Hydrolysis rate}

Acid value $_{(\text {hydrolyzed FOG) }}-$ Acid value $_{\text {(unhydrolyzed FOG) }}$

$=\frac{\text { Saponification value }_{\text {(unhydrolyzed FOG) }}-\text { Acid value }_{\text {(unhydrolyzed FOG) }}}{\text { Ant }}$ $\times 100 \%$

where acid value: the number of milligrams of potassium hydroxide required to neutralize the free fatty acid in one gram of fat, oil, resin, etc.

Saponification value: represents the number of milligrams of potassium hydroxide required to saponify $1.0 \mathrm{~g}$ fat under the conditions specified.

\subsubsection{Biomethane production rate}

The biomethane production rate is calculated according to the following equation:

$k=\frac{\sum_{t=0}^{n} D_{t}}{n}$

where $k$ represents the biomethane production rate $(\mathrm{mL} / \mathrm{d}) ; t$ is the digestion time (d); $D_{t}$ stands for the daily biomethane production $(\mathrm{mL}) ; n$ refers to the day when the daily biomethane production is less than $5 \%$ of the maximum daily biomethane production for five days.

\section{Results and discussion}

\subsection{Enzymatic hydrolysis conditions}

According to the application conditions provided by the lipase manufacturer in Table 1, the scopes of main parameters have been confirmed. However, an accurate condition would enhance the efficiency of the hydrolysis and save both time and cost. So the first step in this study was to optimize parameters like hydrolysis time, the amount of additive and temperature.

\subsubsection{Enzymatic hydrolysis time}

Enzymatic hydrolysis time is an important factor that determines the hydrolysis rate (Masse et al., 2001). The main purpose of this part was to determine the time that guaranteed FOG was hydrolyzed by lipases completely.

AF, VO and FG were pre-treated by three lipases (Table 1 ) at different hydrolysis time. The hydrolysis rates of AF, VO and FG were show in Fig. 1. For AF pre-treated by three lipases (Fig. 1(A)), the hydrolysis rates revealed increasing trends when the hydrolysis time increased from $1 \mathrm{~h}$ to $4 \mathrm{~h}$. After $4 \mathrm{~h}$, the hydrolysis rates of AF-I and AF-II were leveling off in the range of $62.0-74.4 \%$ and 69.9-79.8\%, respectively. However, the hydrolysis rate of AF-III declined and the maximum value was $25.6 \%$ within $24 \mathrm{~h}$. For VO (Fig. 1(B)), the hydrolysis rates of VO-I and VO-II showed similar trends by rising from $24.6 \%$ to $77.3 \%$ and $36.7 \%$ to $86.0 \%$ within $36 \mathrm{~h}$, respectively. When the VO was pre-treated by Lipase III, the
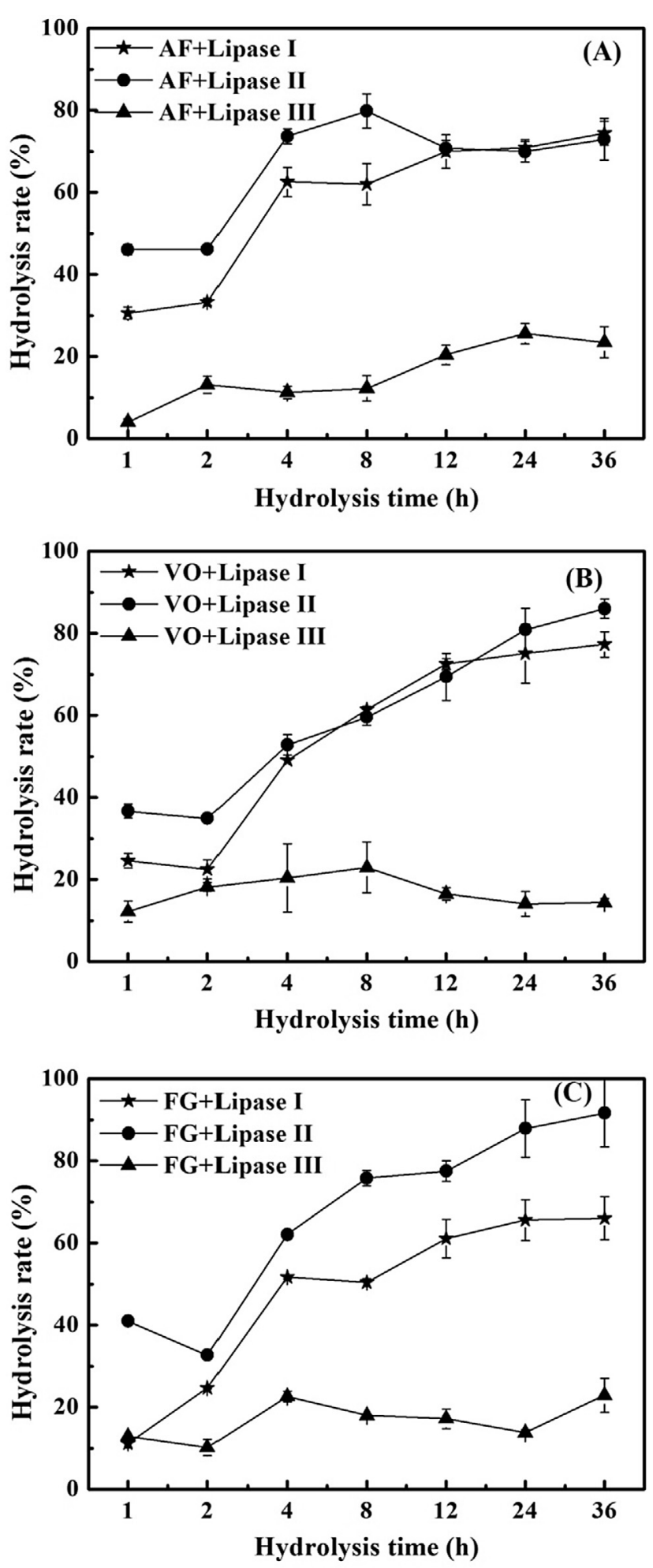

Fig. 1. The hydrolysis rates of FOG with three lipases addition at different hydrolysis time: $(\mathrm{A})$ animal fat (AF) with lipase I, II and III addition between 1 and $36 \mathrm{~h}$; (B) vegetable oil (VO) with lipase I, II and III addition between 1 and $36 \mathrm{~h}$; (C) floatable grease (FG) with lipase I, II and III addition between 1 and $36 \mathrm{~h}$.

rate of hydrolysis was ranged $12.2-22.9 \%$ from 1 to 36 h duration. For FG, the hydrolysis rate of FG-III also appeared low hydrolysis rate during $36 \mathrm{~h}$ (12.9-22.9\%). As time goes, hydrolysis rates of FG-I and FG-II also present similar increasing trend with pretreated $\mathrm{AF}$ and VO. When the hydrolysis time increased from $24 \mathrm{~h}$ to $36 \mathrm{~h}$, there was no apparently enhancement both for FG-I and FG-II. 
It could be concluded that $\mathrm{AF}$, VO and FG were adequately hydrolyzed by Lipase-I and Lipase-II after the hydrolysis time reached $24 \mathrm{~h}$. When the hydrolysis time increased to $36 \mathrm{~h}$, there was no significant difference on the rates hydrolysis. It illustrated that the hydrolysis has reached equilibrium. For Lipase-III, the hydrolysis rate was less affected by the hydrolysis time. When the poultry slaughterhouse effluent was pretreated by lipase from fungus, the hydrolysis time of $22 \mathrm{~h}$ was chosen (Valladão et al.,
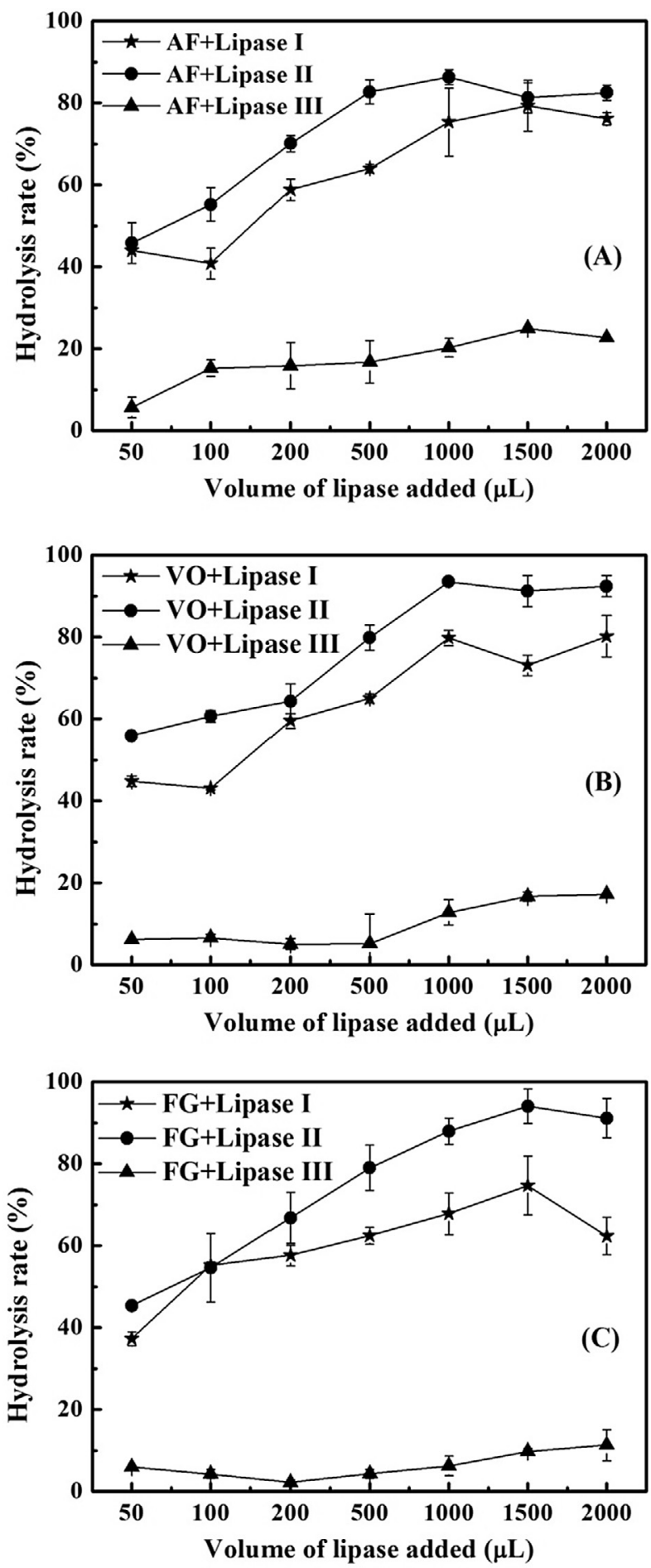

Fig. 2. The hydrolysis rates of FOG with different volume of three lipases added. The hydrolysis time was $24 \mathrm{~h}$. (A) AF was hydrolyzed with different volume of lipase I, Il and III; (B) VO was hydrolyzed with different volume of lipase I, II and III; (C) FG was hydrolyzed with different volume of lipase I, II and III.
2007). In this study, the optimal hydrolysis time of $24 \mathrm{~h}$ was enough.

\subsubsection{Volume of lipase added}

When AF, VO and FG were pretreated with different volumes of lipase, the consecutive changes of hydrolysis rates are presented in
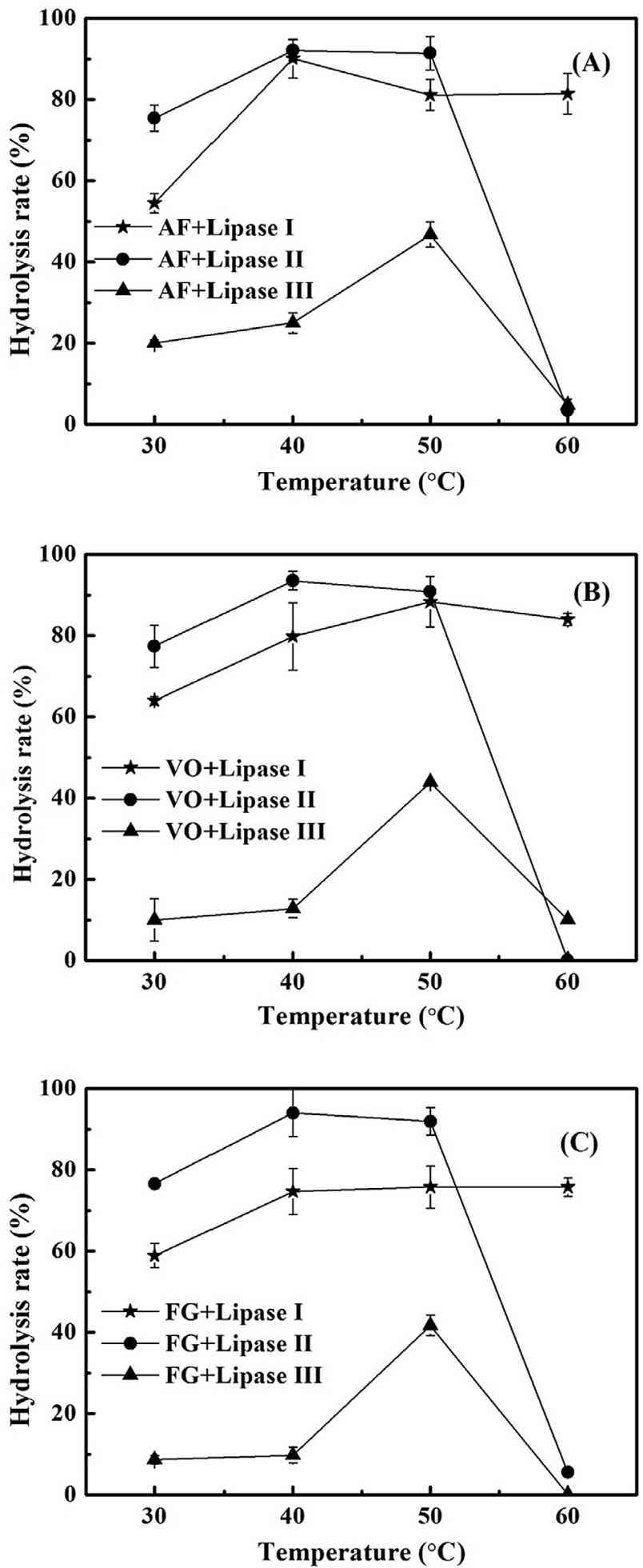

Fig. 3. The hydrolysis rates of FOG at different temperatures $\left(30^{\circ} \mathrm{C}, 40^{\circ} \mathrm{C}, 50^{\circ} \mathrm{C}\right.$ and $60{ }^{\circ} \mathrm{C}$ ). The volume of lipases was $1000 \mu \mathrm{L}$ and the hydrolysis time was $24 \mathrm{~h}$. (A) AF was hydrolyzed by Lipase I, II and III; (B) VO was hydrolyzed by Lipase I, II and III; (C) FG was hydrolyzed by Lipase I, II and III. 


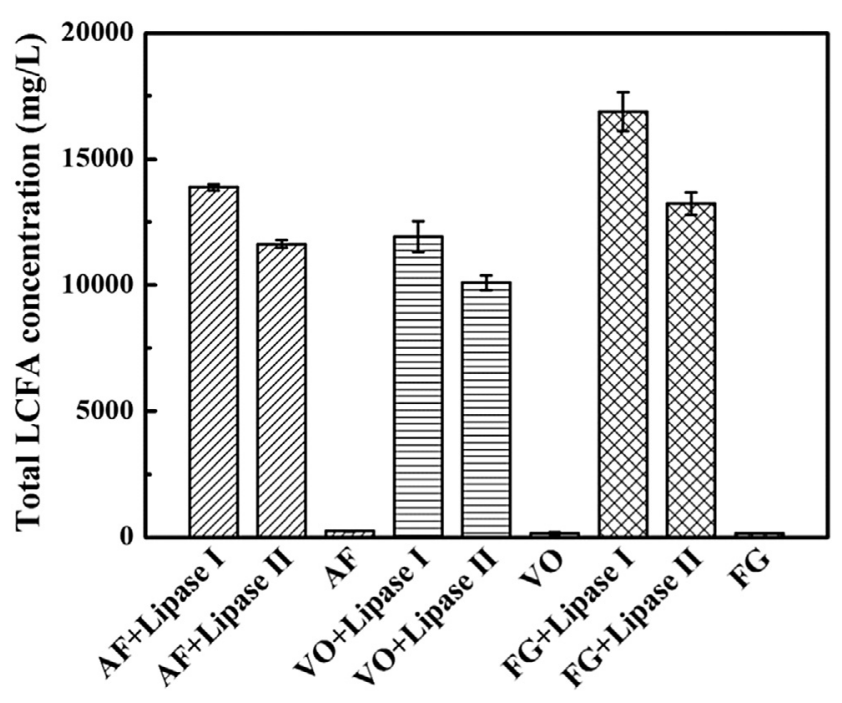

Fig. 4. Total LCFA concentrations of AF, VO and FG after treating by Lipase-I and Lipase-II.

Fig. 2. It shows that, the hydrolysis rates have been enhanced when the volume of lipase increased. As for $\mathrm{AF}$, when the volume of Lipase-I and Lipase-II increased from $50 \mu \mathrm{L}$ to $2000 \mu \mathrm{L}$, the hydrolysis rates also showed increasing trend (Fig. 2(A)). The maximum hydrolysis rates of AF were $79.3 \%(1500 \mu \mathrm{L}$, Lipase-I) and $86.3 \%$ $(1000 \mu \mathrm{L}$, Lipase-II). When the volumes were in the range of $1000-2000 \mu \mathrm{L}$, the hydrolysis rate of AF varies very little for both Lipase-I and Lipase-II. The turning point also was $1000 \mu \mathrm{L}$ for both VO-I and VO-II. For FG, the highest hydrolysis rate obtained when it was treated by $1500 \mu \mathrm{L}$ Lipase-I and Lipase-II. When Lipase-I and Lipase-II were increased to $2000 \mu \mathrm{L}$, there was no obvious enhancement both for AF and VO. The results was consistent with Valladão's study (Valladão et al., 2007). However, the hydrolysis rates of $\mathrm{AF}, \mathrm{VO}$ and FG treated by Lipase-III were less than $22 \%$ with the amount of Lipase-III increasing to $2000 \mu \mathrm{L}$. It shows that, increasing the amount of Lipase-III could not improve the hydrolysis rate of FOG, obviously.

Another phenomenon was observed in Fig. 2. The line of LipaseI was always upon the line of Lipase-II for AF, VO and FG. And the Lipase-III lines were on the bottom all the time. When the volume was $100-1000 \mu \mathrm{L}$, the hydrolysis rate of AF-II was higher than that of AF-I. As the volume increasing to $1500 \mu \mathrm{L}$, the hydrolysis rates were almost same for AF-I and AF-II. Hydrolysis rates of VO-II were higher than that of VO-I when the same volume of lipase was added. It should be connected with the production process of the lipase. The main raw materials of Lipase-II were refined vegetable oil and vegetable protein. In terms of FG, the highest hydrolysis rate $(94.0 \%)$ was obtained when it was treated by $1500 \mu \mathrm{L}$ Lipase-II, which was $27.0 \%$ higher than that of FG-I $(74 \%, 1500 \mu \mathrm{L}$ Lipase-I). The trends of three FG lines were consistent with AF and VO, that's because the main contents of FG were AF and VO.

Based on these results, Lipase-I and Lipase-II were more suitable than Lipase-III for pretreatment of FOG. The recommended volumes of lipase addition were advised as $1000-1500 \mu \mathrm{L}$ for $\mathrm{AF}$, VO and FG.

\subsubsection{Temperature}

Temperature also is one of very important parameters to determine the activity of lipase (Mahadik et al., 2002). Lipase activity would be enhanced when temperature increases. However, excess temperature could lead to the loss of the lipase activity (dos Prazeres et al., 2006). In this study, the hydrolysis rate of FOG was used to reflect the lipase activity at different temperatures (Fig. 3).

Table 2

The hydrolysis products of AF, VO and FG which were treated by Lipase-I and Lipase-II (the unit is $\mathrm{mg} / \mathrm{L}$ ).

\begin{tabular}{|c|c|c|c|c|c|c|c|c|c|}
\hline \multirow[t]{2}{*}{ LCFA } & \multicolumn{3}{|l|}{$\mathrm{AF}$} & \multicolumn{3}{|l|}{ VO } & \multicolumn{3}{|l|}{ FG } \\
\hline & Control & Lipase-I & Lipase-II & Control & Lipase-I & Lipase-II & Control & Lipase-I & Lipase-II \\
\hline C10:0 & nd & $1.6 \pm 0.4$ & $7.2 \pm 0.5$ & nd & $12.2 \pm 1.5$ & $\mathrm{Nd}$ & nd & $1.3 \pm 0.2$ & nd \\
\hline $\mathrm{C} 11: 0$ & nd & nd & $5.3 \pm 0.6$ & nd & nd & $5.6 \pm 0.5$ & nd & $4.4 \pm 0.7$ & $8.0 \pm 0.2$ \\
\hline $\mathrm{C} 12: 0$ & nd & nd & $16.7 \pm 2.6$ & nd & $17.6 \pm 1.3$ & $13.2 \pm 0.9$ & nd & $12.0 \pm 0.7$ & $23.2 \pm 3.7$ \\
\hline C13:0 & nd & nd & $11.1 \pm 0.4$ & nd & nd & $4.2 \pm 0.5$ & nd & $1.8 \pm 0.2$ & $14.7 \pm 1.9$ \\
\hline C14:0 & $2.8 \pm 0.3$ & $6.9 \pm 0.1$ & $119.5 \pm 3.2$ & nd & $164.9 \pm 5.1$ & $4.8 \pm 0.1$ & nd & $53.6 \pm 3.2$ & $43.3 \pm 0.7$ \\
\hline C14:1 & nd & $2.3 \pm 0.2$ & $2.4 \pm 0.4$ & nd & $1.4 \pm 0.1$ & $3.0 \pm 0.5$ & nd & $4.0 \pm 0.2$ & $13.9 \pm 1.4$ \\
\hline $\mathrm{C} 15: 0$ & nd & $2.4 \pm 0.4$ & $6.0 \pm 0.3$ & nd & $9.7 \pm 1.6$ & $11.8 \pm 0.5$ & nd & $11.4 \pm 0.5$ & $25.2 \pm 4.2$ \\
\hline C15:1(7) & nd & nd & $1.7 \pm 0.1$ & nd & $2.9 \pm 0.4$ & $9.0 \pm 1.8$ & nd & $2.9 \pm 0.1$ & $18.4 \pm 3.1$ \\
\hline $\mathrm{C} 16: 0$ & $34.6 \pm 0.2$ & $3006.1 \pm 12.6$ & $1883.6 \pm 65.4$ & $5.6 \pm 0.3$ & $2502.9 \pm 129.4$ & $1948.1 \pm 41.2$ & $5.6 \pm 0.3$ & $3579.7 \pm 180.2$ & $2451.7 \pm 87.8$ \\
\hline C16:1(9) & $9.0 \pm 0.4$ & $21.8 \pm 1.5$ & $236.7 \pm 5.3$ & $1.0 \pm 0.2$ & $236.8 \pm 14.4$ & $16.0 \pm 2.0$ & nd & $119.7 \pm 3.6$ & $101.5 \pm 3.2$ \\
\hline C17:0 & nd & $17.7 \pm 0.6$ & $62.6 \pm 7.3$ & nd & $58.8 \pm 5.2$ & $14.7 \pm 1.3$ & nd & $37.7 \pm 0.4$ & $43.1 \pm 1.4$ \\
\hline C17:1(10) & $1.2 \pm 0.1$ & $9.9 \pm 2.3$ & $50.8 \pm 1.3$ & nd & $40.6 \pm 2.7$ & $9.5 \pm 1.5$ & nd & $28.6 \pm 1.2$ & $43.8 \pm 1.6$ \\
\hline $\mathrm{C} 18: 0$ & $25.5 \pm 0.4$ & $830.9 \pm 7.4$ & $2769.8 \pm 86.9$ & $3.3 \pm 1.1$ & $3268.4 \pm 172.2$ & $673.0 \pm 28.7$ & $2.1 \pm 0.4$ & $1447.0 \pm 67.4$ & $1128.8 \pm 40.4$ \\
\hline C18:1(9) & $42.2 \pm 0.8$ & $4885.9 \pm 17.5$ & $3301.5 \pm 115.9$ & $5.9 \pm 0.2$ & $2929.7 \pm 151.4$ & $3468.1 \pm 61.2$ & $16.1 \pm 0.3$ & $3312.6 \pm 156.2$ & $2565.3 \pm 94.6$ \\
\hline C18:2(9,12) & $23.6 \pm 0.5$ & $3531.4 \pm 55.1$ & $1811.3 \pm 130.8$ & $11.0 \pm 0.4$ & $1322.8 \pm 42.7$ & $2159.7 \pm 38.2$ & $15.1 \pm 0.4$ & $5543.2 \pm 274.4$ & $4146.7 \pm 122.0$ \\
\hline C18:3(6,9,12) & nd & $5.2 \pm 0.8$ & $23.0 \pm 0.3$ & $6.8 \pm 1.0$ & $23.3 \pm 0.9$ & $36.4 \pm 5.6$ & $6.2 \pm 1.4$ & $28.9 \pm 3.5$ & $64.3 \pm 11.8$ \\
\hline $\mathrm{C} 18: 3(9,12,15)$ & $2.2 \pm 0.2$ & $22.0 \pm 1.2$ & $147.8 \pm 2.6$ & $21.4 \pm 2.7$ & $136.1 \pm 9.6$ & $54.3 \pm 1.7$ & $11.8 \pm 0.5$ & $1683.5 \pm 63.0$ & $1173.2 \pm 41.2$ \\
\hline $\mathrm{C} 20: 0$ & $4.7 \pm 0.1$ & $344.1 \pm 5.1$ & $64.1 \pm 1.1$ & $22.3 \pm 3.5$ & $94.5 \pm 4.0$ & $331.6 \pm 30.2$ & $18.2 \pm 0.6$ & $125.7 \pm 2.8$ & $169.9 \pm 3.2$ \\
\hline C20:1(11) & $1.6 \pm 0.2$ & $277.9 \pm 9.2$ & $151.4 \pm 8.3$ & $19.0 \pm 2.2$ & $243.2 \pm 7.5$ & $244.0 \pm 7.0$ & $11.9 \pm 2.2$ & $174.0 \pm 6.4$ & $239.2 \pm 6.0$ \\
\hline C20:2 & $4.3 \pm 0.5$ & $18.2 \pm 1.3$ & $139.2 \pm 6.2$ & $21.1 \pm 3.2$ & $153.9 \pm 25.1$ & $37.2 \pm 3.8$ & $14.2 \pm 1.6$ & $69.1 \pm 5.8$ & $100.1 \pm 7.2$ \\
\hline C20:3 $(11,14,17)$ & nd & $1.9 \pm 0.4$ & $15.1 \pm 1.5$ & $1.1 \pm 0.5$ & $21.0 \pm 1.8$ & $22.0 \pm 1.0$ & nd & $17.5 \pm 2.3$ & $47.6 \pm 2.5$ \\
\hline $\mathrm{C} 20: 3$ & $1.6 \pm 0.1$ & nd & $70.8 \pm 6.3$ & nd & $85.0 \pm 5.4$ & $\mathrm{Nd}$ & nd & $37.7 \pm 2.5$ & $62.6 \pm 2.0$ \\
\hline $\mathrm{C} 20: 4(5,8,11,14)$ & nd & $9.8 \pm 1.1$ & $12.6 \pm 1.0$ & nd & $4.0 \pm 0.6$ & $5.6 \pm 0.1$ & nd & $14.7 \pm 2.2$ & $79.7 \pm 5.7$ \\
\hline $\mathrm{C} 20: 5$ & nd & $305.5 \pm 1.9$ & $12.3 \pm 0.9$ & nd & $2.3 \pm 0.1$ & $294.3 \pm 23.8$ & nd & $38.2 \pm 1.8$ & $70.1 \pm 5.2$ \\
\hline $\mathrm{C} 22: 0$ & nd & $39.4 \pm 2.5$ & $11.3 \pm 1.3$ & nd & $26.7 \pm 3.5$ & $41.8 \pm 1.2$ & nd & $38.9 \pm 1.6$ & $116.4 \pm 2.3$ \\
\hline $\mathrm{C} 22: 1$ & $38.1 \pm 0.3$ & $190.7 \pm 5.1$ & $603.4 \pm 34.7$ & $34.2 \pm 4.1$ & $469.1 \pm 27.0$ & $373.8 \pm 32.3$ & $28.7 \pm 0.8$ & $377.9 \pm 32.3$ & $302.0 \pm 4.4$ \\
\hline $\mathrm{C} 22: 2$ & $6.0 \pm 0.7$ & $10.3 \pm 1.8$ & $47.9 \pm 2.8$ & $1.6 \pm 0.1$ & $30.1 \pm 2.5$ & $12.5 \pm 2.5$ & nd & $23.4 \pm 0.5$ & $86.7 \pm 2.0$ \\
\hline $\mathrm{C} 23: 0$ & $45.8 \pm 3.5$ & $332.5 \pm 2.3$ & $45.3 \pm 5.3$ & $17.7 \pm 0.6$ & $67.3 \pm 5.0$ & $293.3 \pm 18.0$ & $40.9 \pm 1.1$ & $77.6 \pm 5.7$ & $93.3 \pm 5.4$ \\
\hline $\mathrm{C} 24: 0$ & nd & $2.6 \pm 0.2$ & $5.1 \pm 0.9$ & nd & 0.7 & $1.4 \pm 0.1$ & nd & $3.5 \pm 0.6$ & $1.0 \pm 0.1$ \\
\hline
\end{tabular}

nd, no detected. 
Three lipase-lines in Fig. 3(A), (B) or (C) were all presented similar tendency. When the FOG was treated by Lipase-I, the hydrolysis rates all increased with temperature rising. The lowest Lipase-I activity was obtained at $30^{\circ} \mathrm{C}$. In terms of Lipase-II, the hydrolysis rate of FOG was elevated with the temperature from $30^{\circ} \mathrm{C}$ to $50^{\circ} \mathrm{C}$. As it can be observed from Fig. 3, a sharp falling of hydrolysis rate appeared when the temperature reaches $60^{\circ} \mathrm{C}$. For Lipase-III, the hydrolysis rate of FOG changed a little when the temperature rose from $30^{\circ} \mathrm{C}$ to $40^{\circ} \mathrm{C}$. Nevertheless, when the temperature rose up to $50{ }^{\circ} \mathrm{C}$, the hydrolysis rate achieved $46.7 \%, 43.9 \%$ and $41.7 \%$ for $\mathrm{AF}$, VO and FG, respectively. Then the hydrolysis rate of FOG decreased when the temperature reached $60^{\circ} \mathrm{C}$, which illustrate that LipaseIII loses its activity at high temperature. This result is consistent with previous study $\left(40-60^{\circ} \mathrm{C}\right.$ ) (Xavier Malcata et al., 1992), suggesting that high temperature lead to decrease of the hydrolysis rate of FOG. In brief, temperature had significant influence on lipase activity. For Lipase-I and Lipase-II, $40-50{ }^{\circ} \mathrm{C}$ was chosen to hydrolyze FOG. The optimum hydrolysis temperature of Lipase-III was $50^{\circ} \mathrm{C}$.

Although, when the temperature achieved $50^{\circ} \mathrm{C}$, an observable improvement on Lipase-III has been achieved, the hydrolysis rates (41.7-46.7\%) are still much lower than those of Lipase-I and Lipase-II. Lipase-III is natural lipase that extracted from porcine pancreas. Maybe high positional specificity of natural lipase is the reason that leads to low hydrolysis rate. Specificity is a comparative difference in rates of hydrolysis in certain reactions for different lipases (Jensen et al., 1983). In the study of Cavaleiro, enzymatic pretreatment only released $26-33 \%$ of the LCFA (Cavaleiro et al., 2013). Compared with Lipase-III, Lipase-I and Lipase-II are less specific, which leads to higher hydrolysis rate.

Comparing the hydrolysis rates of FOG, Lipase-I and Lipase-II were chosen for the pretreatment ahead of anaerobic digestion. After analyzing the effects of hydrolysis time, volumes added and temperature on the hydrolysis rate of FOG, suitable conditions had been achieved, such as: $24 \mathrm{~h}, 1000-1500 \mu \mathrm{L}$ and $40-50{ }^{\circ} \mathrm{C}$, respectively.

\subsection{Hydrolysis products}

For a convenient operation and comparison of two lipases, the hydrolysis conditions were fixed $\left(24 \mathrm{~h}, 1000 \mu \mathrm{L}\right.$ and $\left.40^{\circ} \mathrm{C}\right)$. Under these conditions, the hydrolysis products of FOG were analyzed by GC. Total LCFA concentration was calculated for each FOG treated with two different lipases. The LCFA concentrations of control AF, VO and FG were also measured as control (Fig. 4). There was only $200 \mathrm{mg} / \mathrm{L}$ free LCFA in the control FOG. The results show that the total LCFA of FOG treated by Lipase-I was 18.2-27.5\% higher than Lipase-II treated FOG. When FOG treated by Lipase-I, the total LCFA of FG-I was $16871.9 \mathrm{mg} / \mathrm{L}$ which was higher than that of AF-I $(13877.3 \mathrm{mg} / \mathrm{L})$ and VO-I $(11925.9 \mathrm{mg} / \mathrm{L})$. Total LCFA of FG-II $(13233.5 \mathrm{mg} / \mathrm{L}$ ) was $13.8 \%$ higher than that of AF-II and $31.2 \%$ higher than that of VO-II. The differences between each FOG were mainly due to the characteristics of AF, VO and FG. FG was mixture of different kinds of animal fat and vegetable oil, which maybe the reason why total LCFA of FOG was higher than that of single AF or VO.

Table 2 shows the hydrolysis products of Lipase-I and Lipase-II treated AF, VO and FG. The carbon chain length of LCFA was in the range of 10-24. Majority of fatty acids were C16 and C18 (set in bold in Table 2), which were $88.3 \%$ and $83.9 \%$ for AF-I and AF-II, respectively. For VO-I and VO-II, the percentages of C16 and C18 were also over $80 \%$. These results were consistent with literature values (Neves et al., 2009; Valladao et al., 2011). In the case of FG, the hydrolysis products after Lipase-I and Lipase-II treatment were greater than those of control AF and VO. Specifically, the content of C18:3(9,12,15) had achieved $1683.5 \mathrm{mg} / \mathrm{L}$ and $1173.2 \mathrm{mg} / \mathrm{L}$ for FG-I and FG-II, respectively. The possible reason could be that different food materials are mixed according to different recipes during cooking process. So the composition and properties of FG was complex.
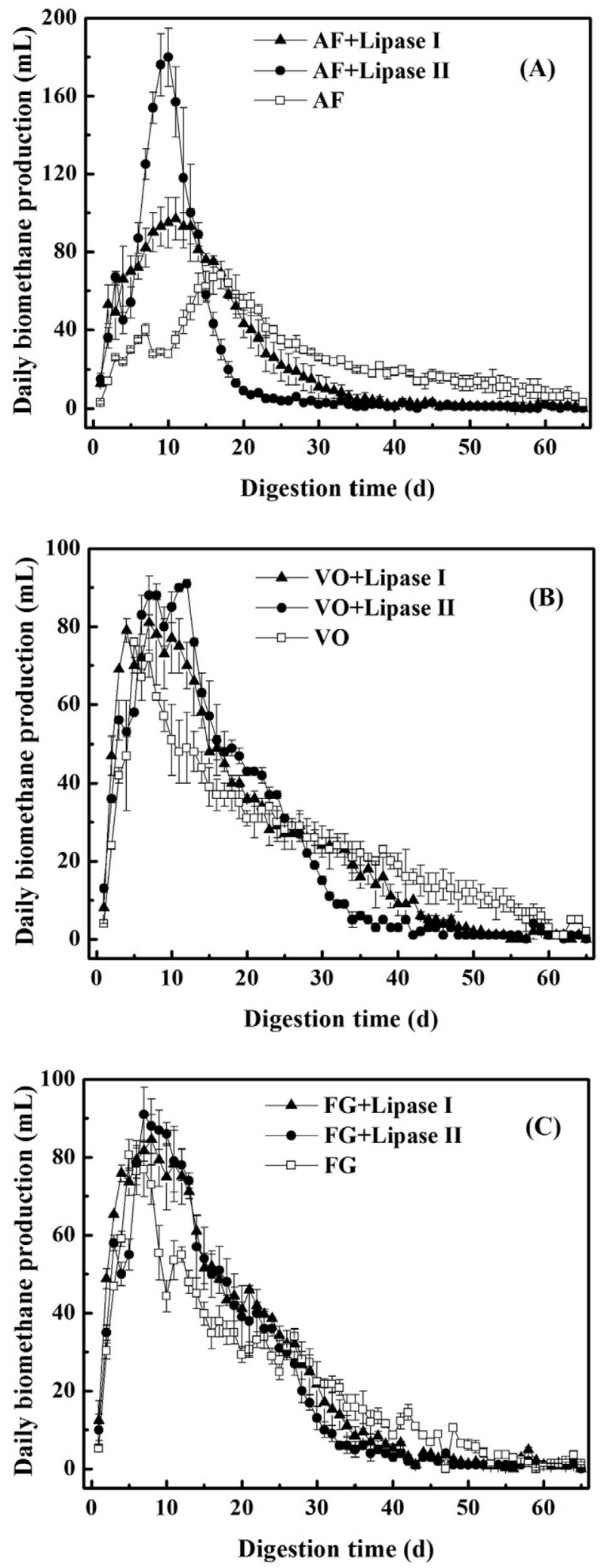

Fig. 5. Daily biomethane production of FOG that treated by Lipase-I and Lipase-II. 
Table 3

The maximum daily biomethane production and biomethane production rate under different experimental conditions.

\begin{tabular}{|c|c|c|c|c|}
\hline \multirow[t]{2}{*}{ Reaction description } & \multirow{2}{*}{$\begin{array}{l}\text { The maximum of daily } \\
\text { biomethane production }(\mathrm{mL})\end{array}$} & \multirow{2}{*}{$\sum_{t=0}^{n} D_{t}(\mathrm{~mL})$} & \multicolumn{2}{|c|}{ Biomethane production rate } \\
\hline & & & $n(\mathrm{~d})$ & $k(\mathrm{~mL} / \mathrm{d})$ \\
\hline AF + Lipase I & $97 \pm 11$ & $1695 \pm 19$ & $0-36$ & $47 \pm 1$ \\
\hline AF + Lipase II & $180 \pm 22$ & $1601 \pm 87$ & $0-24$ & $67 \pm 4$ \\
\hline AF & $68 \pm 7$ & $1688 \pm 27$ & $0-64$ & $26 \pm 1$ \\
\hline VO + Lipase I & $81 \pm 7$ & $1696 \pm 53$ & $0-52$ & $33 \pm 1$ \\
\hline VO + Lipase II & $91 \pm 1$ & $1615 \pm 79$ & $0-40$ & $40 \pm 2$ \\
\hline VO & $72 \pm 5$ & $1640 \pm 43$ & $0-64$ & $26 \pm 1$ \\
\hline FG + Lipase I & $85 \pm 6$ & $1704 \pm 2$ & $0-46$ & 37 \\
\hline FG + Lipase II & $91 \pm 7$ & $1562 \pm 104$ & $0-41$ & $38 \pm 3$ \\
\hline FG & $81 \pm 4$ & $1519 \pm 31$ & $0-56$ & $27 \pm 2$ \\
\hline
\end{tabular}

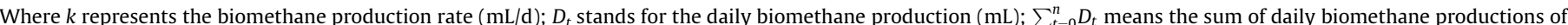
the days between 0 and $n ; n$ refers to the day when the daily biomethane production is less than $5 \%$ of the maximum daily biomethane production for five days.

Hydrolysis was the first step in anaerobic digestion of FOG. Also, hydrolysis was the rate limiting step in the process of anaerobic digestion (Meng et al., 2015a; Sun et al., 2014). A study showed that through $\beta$-oxidation, hydrolysis products (LCFA) could be degraded to VFA, which could be used directly by methanogens (Ziels et al., 2015). And then the performances of anaerobic digestions between hydrolysis products of FOG treated by lipases and control FOG would be compared.

\subsection{Anaerobic digestion performance}

In this part, anaerobic digestions of $\mathrm{AF}, \mathrm{VO}$ and $\mathrm{FG}$ treated by Lipase-I and Lipase-II would be compared with that of control materials without lipase addition. Daily biomethane production and biomethane production rate would be discussed subsequently to clarify the benefits of lipase addition.

\subsubsection{Daily biomethane production}

The biomethane content was in the range of $65-70 \%$. Daily biomethane production has been presented in Fig. 5 and Table 3. In Fig. 5(A), there is a sharp peak of AF-II which shows the maximum biomethane production achieved $180 \mathrm{~mL}$ on the 10th day, which was $85.6 \%$ higher than the peak value of AF-I ( $97 \mathrm{~mL}, 11$ th day). For the control AF, not only the peak value $(68 \mathrm{~mL})$ was much less than that of AF-I and AF-II, but also 6-7 days' time lag were appeared. When VO was treated by Lipase-I and Lipase-II, the maximum value $(81 \mathrm{~mL}$ and $91 \mathrm{~mL}$, respectively) was $12.5-26.4 \%$ higher than that of control VO $(72 \mathrm{~mL})$. Although, the early crest value was appeared for control FG on 5th day, the daily biomethane production decreased subsequently. When FG was treated by Lipase I and Lipase II, there were longer high-biomethaneproduction stages for FG-I and FG-II than that of control Mendes et al. (2006) also reported that the use enzymatic treatment could increase the biogas production.

Generally, the daily biomethane production of FOG could be enhanced by lipase pretreatment. For AF and VO, the peak values appeared earlier than that of controls.

\subsubsection{Biomethane production rate}

When the daily biomethane production was less than the maximum of daily biomethane production for five days, the value of $n$ was obtained. Then the daily biomethane production from day- 0 to day- $n$ would be summed $\left(\sum_{t=0}^{n} D_{t}\right)$ that shown in Table 3 . The values of $\sum_{t=0}^{n} D_{t}$ for both AF and VO were in the range of 1601$1696 \mathrm{~mL}$. And the values of $n$ and $k$ for control AF and control VO are both $0-64 \mathrm{~d}$ and $26 \pm 1 \mathrm{~mL} / \mathrm{d}$. However, when AF and VO were treated by Lipase I, the values of $n$ were reduced to $36 \mathrm{~d}$ and $52 \mathrm{~d}$, respectively. The biomethane production rates $(k)$ of AF-I and VO-I were enhanced $80.8 \%$ and $26.9 \%$, respectively. When AF and VO are treated by Lipase II, the values of $n$ are reduced to $24 \mathrm{~d}$ and $40 \mathrm{~d}$, respectively. The biomethane production rate for AF-II is more than twice as that of control AF. The value of VO-II was 1.5 times better than that of control VO. FG was the mixture of AF and VO. When FG was treated by Lipase I and Lipase II, not only the values of $n$ were shortened, but also the values of $\sum_{t=0}^{n} D_{t}$ were increased. Therefore, the biomethane production rates of FG-I and FG-II are enhanced $37-41 \%$ than that of control FG.

It could be concluded that, when the FOG was treated by lipase, the biomethane production rate would be enhanced. During the whole process, the lipase pretreatment accelerated the hydrolysis of FOG. Compared with the control FOG, more LCFA was obtained from lipase treated FOG. Then FOG was transformed into macromolecules those were easier utilized by microorganism. The results of this study, along with others (Alexandre et al., 2011; Rosa et al., 2009), suggest that the efficiency of degradability could be enhanced by shortening digestion time.

Lipids accumulation in the anaerobic digestion would cause serious inhibition (Rasit et al., 2015; Sun et al., 2014). Usually, the lipids were removed by hydrothermal method before anaerobic digestion to avoid lipids accumulation (Meng et al., 2014). However, it was found that the biogas yield of lipids in the food waste was $29.0 \%$ higher than that of rest food waste (Meng et al., 2015b). This study provided another pretreated strategy to enhance the biomethane yield of food waste and the strategy will be reference for similar applying.

\section{Conclusions}

FOG pretreated by lipases could promote hydrolysis rate and enhance biomethane production rate. Lipase-I and Lipase-II obtained could achieve the best hydrolysis result in the conditions of $24 \mathrm{~h}, 1000-1500 \mu \mathrm{L}$ and $40-50{ }^{\circ} \mathrm{C}$. The biomethane production rates were increased by $80.8-157.7 \%, 26.9-53.8 \%$, and $37.0-40.7 \%$ for $\mathrm{AF}, \mathrm{VO}$, and FG, respectively, and the digestion time was shortened by $10-40 \mathrm{~d}$. The finding suggests that pretreating lipids with appropriate lipase could be one of effective methods for enhancing anaerobic digestion of food waste rich in crude lipid.

\section{Acknowledgements}

This work was supported by the National Science \& Technology Pillar Program during the 12th Five-year Plan (2014BAC24B01).

\section{References}

Alexandre, V.M.F., Valente, A.M., Cammarota, M.C., Freire, D.M.G., 2011 Performance of anaerobic bioreactor treating fish-processing plant wastewater pre-hydrolyzed with a solid enzyme pool. Renewable Energy 36 (12), 3439-3444. 
Cavaleiro, A.J., Ferreira, T., Pereira, F., Tommaso, G., Alves, M.M., 2013. Biochemical methane potential of raw and pre-treated meat-processing wastes. Bioresour. Technol. 129, 519-525.

Chen, Y., Cheng, J.J., Creamer, K.S., 2008. Inhibition of anaerobic digestion process: a review. Bioresour. Technol. 99 (10), 4044-4064.

Cho, C.-H., Lee, B., Lee, Y.-W., 2016. The treatment of source separated food waste by mesophilic anaerobic digestion system with leachate recirculation. J. Korea Org. Resource Recycl. Assoc. 24 (1), 31-40.

Dhamodharan, K., Kumar, V., Kalamdhad, A.S., 2015. Effect of different livestock dungs as inoculum on food waste anaerobic digestion and its kinetics. Bioresour. Technol. 180, 237-241.

dos Prazeres, J.N., Cruz, J.A.B., Pastore, G.M., 2006. Characterization of alkaline lipase from Fusarium oxysporum and the effect of different surfactants and detergents on the enzyme activity. Braz. J. Microbiol. 37 (4), 505-509.

Gomes, D.R.S., Papa, L.G., Cichello, G.C.V., Belançon, D., Pozzi, E.G., Balieiro, J.C.C., Monterrey-Quintero, E.S., Tommaso, G., 2011. Effect of enzymatic pretreatment and increasing the organic loading rate of lipid-rich wastewater treated in a hybrid UASB reactor. Desalination 279 (1-3), 96-103.

Jensen, R.G., DeJong, F.A., Clark, R.M., 1983. Determination of lipase specificity. Lipids 18 (3), 239-252.

Lin, C.S.K., Pfaltzgraff, L.A., Herrero-Davila, L., Mubofu, E.B., Abderrahim, S., Clark, J. H., Koutinas, A.A., Kopsahelis, N., Stamatelatou, K., Dickson, F., Thankappan, S. Mohamed, Z., Brocklesby, R., Luque, R., 2013. Food waste as a valuable resource for the production of chemicals, materials and fuels. Current situation and global perspective. Energy Environ. Sci. 6 (2), 426-464.

Luste, S., Luostarinen, S., Sillanpaa, M., 2009. Effect of pre-treatments on hydrolysis and methane production potentials of by-products from meat-processing industry. J. Hazard. Mater. 164 (1), 247-255.

Ma, Y., Zheng, L., Wang, Q., Ma, H., Niu, R., Gao, Z., 2015. Synergistic effect of mixed methanol/ethanol on transesterification of waste food oil using ptoluenesulfonic acid as catalyst. Environ. Progress Sustainable Energy 34 (5), $1547-1553$.

Mahadik, N.D., Puntambekar, U.S., Bastawde, K.B., Khire, J.M., Gokhale, D.V., 2002. Production of acidic lipase by Aspergillus niger in solid state fermentation. Process Biochem. 38, 7.

Masse, L., Kennedy, K.J., Chou, S., 2001. Testing of alkaline and enzymatic hydrolysis pretreatments for fat particles in slaughterhouse wastewater. Bioresour. Technol. 77 (2), 145-155.

Masse, L., Massé, D.I., Kennedy, K.J., 2003. Effect of hydrolysis pretreatment on fat degradation during anaerobic digestion of slaughterhouse wastewater. Process Biochem. 38 (9), 1365-1372.

Mendes, A.A., Pereira, E.B., de Castro, H.F., 2006. Effect of the enzymatic hydrolysis pretreatment of lipids-rich wastewater on the anaerobic biodigestion. Biochem. Eng. J. 32 (3), 185-190.

Meng, Y., Shen, F., Yuan, H., Zou, D., Liu, Y., Zhu, B., Chufo, A., Jaffar, M., Li, X., 2014 Start-up and operation strategies on the liquefied food waste anaerobic digestion and a full-scale case application. Bioprocess Biosyst. Eng. 37 (11), 2333-2341.

Meng, Y., Li, S., Yuan, H., Zou, D., Liu, Y., Zhu, B., Chufo, A., Jaffar, M., Li, X., 2015a. Evaluating biomethane production from anaerobic mono- and co-digestion of food waste and floatable oil (FO) skimmed from food waste. Bioresour. Technol. $185,7-13$.

Meng, Y., Li, S., Yuan, H., Zou, D., Liu, Y., Zhu, B., Li, X., 2015b. Effect of lipase addition on hydrolysis and biomethane production of Chinese food waste. Bioresour. Technol. 179, 452-459.

Naroznova, I., Møller, J., Scheutz, C., Lagerkvist, A., 2015. Importance of food waste pre-treatment efficiency for global warming potential in life cycle assessment of anaerobic digestion systems. Resour. Conserv. Recycl. 102, 58-66.

Neves, L., Pereira, M.A., Mota, M., Alves, M.M., 2009. Detection and quantification of long chain fatty acids in liquid and solid samples and its relevance to understand anaerobic digestion of lipids. Bioresour. Technol. 100 (1), 91-96.

Rasit, N., Idris, A., Harun, R., Wan Ab Karim Ghani, W.A., 2015. Effects of lipid inhibition on biogas production of anaerobic digestion from oily effluents and sludges: an overview. Renewable Sustainable Energy Rev. 45, 351-358.

Rosa, D.R., Duarte, I.C., Saavedra, N.K., Varesche, M.B., Zaiat, M., Cammarota, M.C. Freire, D.M., 2009. Performance and molecular evaluation of an anaerobic system with suspended biomass for treating wastewater with high fat content after enzymatic hydrolysis. Bioresour. Technol. 100 (24), 6170-6176.

Rosillo-Calle, F., Pelkmans, L., Walter, A. 2009. A global overview of vegetable oils, with reference to biodiesel. A Report for the Bioenergy Task, 40.

Sun, Y., Wang, D., Yan, J., Qiao, W., Wang, W., Zhu, T., 2014. Effects of lipid concentration on anaerobic co-digestion of municipal biomass wastes. Waste Manage. 34 (6), 1025-1034.

Valladão, A.B.G., Freire, D.M.G., Cammarota, M.C., 2007. Enzymatic pre-hydrolysis applied to the anaerobic treatment of effluents from poultry slaughterhouses. Int. Biodeterior. Biodegrad. 60 (4), 219-225.

Valladao, A.B., Torres, A.G., Freire, D.M., Cammarota, M.C., 2011. Profiles of fatty acids and triacylglycerols and their influence on the anaerobic biodegradability of effluents from poultry slaughterhouse. Bioresour. Technol. 102 (14), 70437050 .

Wanasundara, U.N., Shahidi, F., 1998. Lipase-assisted concentration of n-3 polyunsaturated fatty acids in acylglycerols from marine oils. J. Am. Oil Chem. Soc. 75 (8), 945-951.

Wef, A.A., 1998. Standard Methods for the Examination of Water and Wastewater. Washington, DC.

Xavier Malcata, F., Hill, Charles.G., Amundson Jr, C.H., 1992. Hydrolysis of butteroil by immobilized lipase using a hollow-fiber reactor: IV. Effects of temperature. Biotechnol. Bioeng. 39 (11), 1097-1111.

Ziels, R.M., Beck, D.A., Martí, M., Gough, H.L., Stensel, H.D., Svensson, B.H., 2015. Monitoring the dynamics of syntrophic $\beta$-oxidizing bacteria during anaerobic degradation of oleic acid by quantitative PCR. FEMS Microbiol. Ecol. 91 (4), fiv028. 